\title{
Diálogo entre marxismo y psicoanálisis: vigencia del legado de V. N. Voloshinov"
}

\section{Dialogue between Marxism and Psychoanalysis: the Legacy of V. N. Voloshinov}

\begin{tabular}{l|l|l} 
Recibido: marzo 4 de 2010 | Revisado: septiembre 14 de $2010 \quad$ Aceptado: octubre 2 de 2010
\end{tabular}

\author{
F. Manuel Montalbán Peregrín ** \\ Universidad de Málaga, España
}

Para citar este artículo. Montalbán, F. M. (2011). Diálogo entre marxismo y psicoanálisis: vigencia del legado de V. N. Voloshinov. Universitas Psychologica, 10(1), 263-277.

* Artículo teórico.

*** Profesor titular de Psicología Social. Facultad de Estudios Sociales y del Trabajo. Ampliación Campus de Teatimus, s.n. 29071. Málaga, España. E-mail: fmontalban@uma.es

\section{RES UMEN}

El Psicoanálisis hace su entrada tempranamente en Rusia, incluso antes que en muchos países occidentales. El desarrollo de una teoría científica de la psique fue entendido como una prioridad por los científicos sociales marxistas, y las hipótesis freudianas fueron acogidas con interés para esta tarea, antes de que en la década de 1920 la represión política disolviera el movimiento psicoanalítico. El presente escrito se centrará en las aportaciones de Valentin N. Voloshinov, representante del fructífero circulo bajtiniano en el Leningrado posrevolucionario que, a partir de su redescubrimiento, para las Ciencias Sociales en Occidente, cobran un verdadero carácter anticipador en la comprensión de la dialéctica entre lo personal y lo social. Se discutirá, igualmente, cómo la influencia de Voloshinov se deja sentir de manera especial en algunos intentos recientes por reconceptualizar el inconsciente, desde una perspectiva psicosocial.

Palabras clave autor

Psicoanálisis, inconsciente, Voloshinov, Psicología soviética.

Palabras clave descriptores

Valentin Nikolaevič Vološinov, 1895-1936, Crítica e interpretación, Psicoanálisis y

Marxismo, Psicología, Rusia.

\section{A B S T R A C T}

Psychoanalysis appears early in Russia, even before that in many western countries. The development of a scientific theory of the psyche was understood as a priority by the social Marxist scientists and the Freudian hypotheses were received by interest for this task before repression dissolved the psychoanalytic movement at the 1920s. In our case we are going to centre on the contributions of Valentin N. Voloshinov, representative of the fruitful circle bajtiniano in the post-revolutionary Leningrad, which work carries a real anticipating character in the comprehension of the dialectics between the person and the social being from his rediscovery for the social sciences in West. Likewise we will comment how Voloshinov's influence flows especially in some recent attempts for re-conceptualizing the unconscious from a psyco-social perspective.

Key words author

Psychoanalysis, Unconscious, Voloshinov, Soviet Psychology.

Key words plus

Valentin Nikolaevič Vološinov, 1895-1936, Critic and Interpretation, Psychoanalysis and Marxism, Psychology, Rusia. 


\section{Introducción}

La ósmosis inicial entre Psicoanálisis y marxismo se va produciendo, gradualmente, en las dos primeras décadas del siglo XX. Después de la revolución rusa, entre la intelligentsia que regresa del exilio hay analizantes de Freud y sus discípulos que van conformando sociedades e instituciones psicoanalíticas, en varios puntos de la extensa geografía soviética. Se tratará, sin dudas, de uno de los períodos más estimulantes de la creación cultural del siglo XX. La teoría psicoanalítica de Freud es recibida, al igual que en otros países de Europa y América, con gran interés, al tiempo que genera también una importante controversia que, en este caso, se centrará fundamentalmente sobre el estatuto científico del Psicoanálisis y la posibilidad de integración de los mecanismos inconscientes desde una perspectiva materialista. Dicho proceso es animado incluso por el propio camarada Trotsky (1972) que descubre el Psicoanálisis en los años de preguerra. El debate sobre la utilidad que el Psicoanálisis ofrecía a los esfuerzos de constitución de una Psicología propiamente marxista, se prolongó durante estos años entre la crítica, a veces virulenta, y los intentos de asimilación más o menos creativos, pero en 1926 el régimen estalinista comienza a perseguir la práctica psicoanalítica hasta que finalmente en 1936 es prohibida completamente y relegada al ostracismo más absoluto. En este sentido, podemos contraponer una cierta tolerancia conciliatoria de los bolcheviques hacia el Psicoanálisis, sobre todo a partir de una pretendida comunalidad materialista, y la intransigencia del estalinismo, fortificado frente a cualquier amenaza al tipo de autoridad doctrinaria que promovía.

Ciertamente los intentos conciliadores entre marxismo y Psicoanálisis se han convertido en un lugar común con resultados contradictorios y dispares, donde siguen predominando las lecturas simplistas y las ideas prejuiciosas. Pero la inexistencia de una síntesis satisfactoria propicia nuevas aproximaciones. Así, algunos acercamientos recientes invitan a seguir pensando conjuntamente el Psicoanálisis y el marxismo no como dos sistemas conceptuales más al uso, sino a partir de su capacidad crítica y su intención terapéutica de la subjetividad alienada (Acanda, 1998).

En su encuentro con el marxismo, sorprende la variedad de los distintos intentos asimiladores de la obra de Freud, en lo que podemos llamar una "apología marxista" de la misma, en un momento histórico en el que se pretende sentar las bases de una teoría de la mente, solamente esbozada de manera implícita en los escritos de Marx, Engels y Lenin, a partir de una serie de elementos discretos, principios marxistas básicos, ideas desarrolladas en la propia Psicología prerrevolucionaria y en el cuerpo teórico del Psicoanálisis, entre otras inspiraciones. El Psicoanálisis hace su entrada tempranamente en Rusia, incluso antes que en otros países más conectados a la tradición germano-austriaca. La Interpretación de los Sueños es la primera de las obras de Freud traducida al ruso, antes que a otra lengua, en 1904. El interés despertado no se centra solo entre la clase médica, sino que se extiende también, y de manera incluso más profunda, a intelectuales, profesionales y artistas, que son atraídos por las posibilidades de aplicación social y cultural de las ideas freudianas. Así, por ejemplo, las escuelas experimentales de inspiración psicoanalítica de Petrogrado y Moscú, ésta última con Vasily, el hijo de Stalin entre sus alumnos, inauguran sus actividades a comienzos de la década de los veinte. Nombres como los de N. Osipov, T. Rosenthal, M. Reisner, A. Joffe o la propia S. Spielrein se vinculan estrechamente al desarrollo pionero del Psicoanálisis y a la consolidación de su perspectiva y su práctica, en la Rusia zarista prerrevolucionaria y en la URSS inmediatamente posterior al triunfo de la revolución bolchevique.

\section{La apología marxista}

El desarrollo de una teoría científica de la conciencia humana ha sido entendido siempre como una prioridad por los científicos sociales marxistas (Parrington, 1997). Mucho más si tenemos en cuenta que para el marxismo la conciencia de los trabajadores en la sociedad capitalista, se presenta como fenómeno contradictorio. Así, por un lado, se afirma el carácter determinante de la presión 
de la ideología dominante en la configuración de las ideas particulares y, por otro, como establece el propio Marx al referirse al "fetichismo de la mercancía”, se resalta el hecho de que las relaciones sociales son, a un mismo tiempo, reducidas y relanzadas por el capitalismo como relaciones entre cosas, expresión última de la alienación del proletario, expropiado del control sobre los medios de producción y la producción misma de su trabajo, y determinado su destino por la acción impersonal y (auto)regeneradora del mercado. La "alienación" se convierte en concepto esencial para intentar comprender la conciencia de los trabajadores en la sociedad capitalista, considerando como raíz material de la misma el hecho de que la actividad del propio trabajador está separada de éste, como algo ajeno a sí mismo, eternizando de ese modo la pasividad y la resignación como los sentimientos clave de un orden inalterable. La posibilidad de cambio del statu quo pasaría, como precondición para cualquier intención revolucionaria, por la propia transformación de la colectividad laboral en masa activa, lo que inevitablemente conlleva también la transformación de la conciencia de la clase trabajadora. Hay muchos trayectos posibles para cubrir este territorio amplio y complejo. En nuestro caso, vamos a comenzar comentando las aportaciones de V.N. Voloshinov, referente del fructífero círculo de M. Bajtin en el Leningrado posrevolucionario, que a partir de su redescubrimiento para las Ciencias Sociales en Occidente, cobran un verdadero carácter anticipador, interesándose de manera especial por comprender cómo esta clase de transformaciones se generan y toman lugar en la conciencia individual. Aquí es donde el recurso a la hipótesis freudiana del inconsciente, se hace especialmente atractivo y paradójico para la aproximación marxista.

En este contexto, las reacciones al Psicoanálisis son variadas, si bien muchos esfuerzos se dirigieron a su recepción crítica y a la correspondiente traducción y adaptación marxista de ideas tomadas de la Psicología burguesa reaccionaria, de la que para muchos autores el propio Psicoanálisis era representante paradigmático. Se trata, en muchas ocasiones, de modelos paradójicos, más preocupa- dos en establecer un difícil equilibrio ideológico que en ofrecer un análisis profundo de las imposibilidades de ambos enfoques, pero también de sus posibles implicaciones recíprocas. Voloshinov nos ofrece el acercamiento más interesante a esta cuestión, a pesar de que paradójicamente se trate de una aproximación bastante crítica, por no decir virulenta, al freudismo, como movimiento en ciernes, que deja, sin embargo, entrever, desde una necesaria perspectiva histórica, nuevas formas de pensar no solo la relación entre marxismo y Psicoanálisis, sino también la dialéctica entre lo personal y lo social. Las aportaciones de Voloshinov en éste y otros textos, pueden ser consideradas también inspiradoras de la necesidad y posibilidad apuntada por Rossi-Landi (1978) de una novedosa aproximación al marxismo, tanto desde la perspectiva del lenguaje como de la ideología.

A las apologías marxista del Psicoanálisis se refiere Voloshinov (1999) en el capítulo final (el décimo) omitido en algunas ediciones y recuperado acertadamente en la edición en castellano de su Freudismo: un bosquejo crítico de 1927. Al tomar básicamente una perspectiva semiótica, genera una aproximación original a las relaciones entre marxismo y Psicoanálisis, distanciándose grandemente de la mayoría de argumentos ofrecidos por otros autores ante la posibilidad, tal como apuntaba Trotsky (1989) en Literatura y revolución, de que el marxismo pueda albergar al Psicoanálisis, al menos a su "núcleo sano". Supuestamente el materialismo dialéctico después de despojar a la doctrina psicoanalítica de la gruesa capa de subjetivismo que la envolvía, podrá apuntarse una nueva victoria. Este núcleo sano es reiterado inconscientemente por el Psicoanálisis mismo, lo que remite a cimientos más amplios y firmes compatibles con el punto de vista materialista con base en el objetivismo, el monismo materialista, el energeticismo y, finalmente, la dialéctica.

El Psicoanálisis para Bykovskii es la doctrina del inconsciente, de lo que ocurre más allá de los límites del yo, teniendo efectos reales sobre las reacciones orgánicas y convirtiéndose, a veces, en su guía. Pero el inconsciente no se puede estudiar de manera subjetiva, sino que Freud tiene que recurrir 
a las manifestaciones objetivas del inconsciente en la conciencia, sueños, lapsus, síntomas, etc. Esta misma concepción del inconsciente es la que permite referirse al método freudiano como a un enfoque monista (dialéctico), por defender la continuidad psíquica no solamente entre instancias mentales, sino también entre la psique y el soma. Se resalta en este punto la afirmación freudiana de que la función sexual no es puramente mental más de lo que es puramente somática, influyendo tanto sobre la vida psíquica cuanto orgánica. A partir de esta estrecha comunicación psique-soma, la concepción energética y el punto de vista económico de los procesos mentales son llevados al primer plano de la exposición de Bykoskii, por cuanto los considera un ejemplo claro de lo que hoy parecería una compatibilidad difícilmente asumible del Psicoanálisis con la reactología.

A mitad de la década de los veinte, tanto Vygotsky como Luria se sienten especialmente atraídos por el Psicoanálisis como reflejo de un pensamiento verdaderamente intrépido (Brenner, 1999). La defensa que estructura A. R. Luria del Psicoanálisis en su obra El Psicoanálisis como sistema de Psicología monista de 1925, aparecido en el texto Psicología y marxismo compilado por K. P. Kornilov, se centra en el concepto de "personalidad total" (Cole, 1980; Kornilov, 1925). Según este autor, la contribución fundamental del Psicoanálisis reside en la consideración del carácter interrelacionado de las distintas funciones mentales y la integración que posibilita de la mente, en el sistema general de los órganos como actividad ideológicamente determinada. Así, se entiende que frente a la actitud atomizadora de la mayoría de la Psicología académica de la época, el Psicoanálisis toma a la persona como un todo integral, lo que permite el requerimiento básico de la Psicología marxista, abordar al individuo como una fuerza activa en la historia e inseparable de ésta. A la búsqueda de criterios más fácilmente identificables como variables objetivas, Luria no duda en considerar los impulsos, no como concepto exclusivamente psicológico, sino, en un sentido más amplio, con amplias resonancias biológicas, como puente entre lo mental y lo orgánico.
Fridman, por su parte, cuyo trabajo se incluye igualmente en el volumen recopilatorio de 1925 anteriormente citado, centra su análisis en el problema de la formación de las ideologías, como sistema de reflejos inexactos de los motivos o fuentes de la actividad humana, estableciendo un paralelismo entre la concepción marxista al respecto y el Psicoanálisis (Angelini, 2008). Tal paralelismo se concentra en la existencia de un mecanismo racionalizador que tiene como meta ocultar los verdaderos motivos de una aspiración bajo la cubierta de otros más ideales, originados aparentemente en la conciencia. La vinculación entre este proceso y el sistema inconsciente es evidente. La formación del proceso racionalizador responde básicamente a la necesidad de evitar la censura como tendencia de la conciencia que explica la necesidad humana de justificarse. La comprensión de la formación ideológica es entonces idéntica solo que marxismo y freudismo se dedicarían a estudiar facetas diferentes aunque complementarias de este proceso.

Con A. B. Zalkind concluye este trayecto apologista. Sus aportaciones datan del artículo Marxismo y freudismo publicado en 1924 y del volumen La sugestión y la vida del organismo de 1927 (Etkind, 1994). Zalkind representa el interés, un tanto forzado, por dotar de validez marxista a ciertos conceptos del Psicoanálisis a través del recurso reflexológico, valor en alza entre la clase científica soviética de la época. Para este propósito, el autor intenta dejar al desnudo la robustez del Psicoanálisis real, no distorsionado, reflexologizando la teoría sexual. Así, por ejemplo, el principio del placer se entendería como la dotación fisiológica conectada con el mecanismo orgánico de coste mínimo, y estaría constituido por la dotación innata del organismo (reflejos incondicionados) y los hábitos condicionados adquiridos desde el principio de nuestra vida, requiriendo a tal fin un esfuerzo mínimo. También el concepto de desplazamiento recibe un tratamiento reflexológico, pasando a denominarse inhibición. Los reflejos compiten entre ellos y algunos se imponen a costa de la inhibición, el desalojo del resto. Pero no siempre triunfan los reflejos más ventajosos. Cuando se debilita la influencia inhibidora de los estímulos 
que desplazaron al reflejo, éste, bajo la influencia de un nuevo estímulo más poderoso, puede irrumpir de nuevo, si bien hasta entonces, se mantiene en estado potencial, eclipsado por el consciente en el inconsciente. Pero desde esta perspectiva, el inconsciente entonces no pasa de ser nada más que una parte temporalmente inhibida de la dotación refleja global, una especie de depósito de almacenaje de stocks reflejos a la espera de un estímulo vivificador. Después de esta operación queda, como claramente expone Voloshinov en su crítica, el freudismo sin la categoría del inconsciente, sin su referente sexual, sin la teoría de los instintos. En síntesis, "queda un freudismo, sin freudismo" (Voloshinov, 1999, p. 225). Es más, algunos años después en pleno revisionismo estalinista Zalkind, con ocasión del Primer Congreso para el Estudio del Comportamiento del Hombre en 1930, saludó la desaparición del Psicoanálisis en la URSS con base en una incompatibilidad manifiesta con las raíces de la sociedad soviética (Acanda, 1998).

\section{Voloshinov y la crítica marxista del freudismo}

La obra de Voloshinov parte de presupuestos totalmente diferentes a los hasta aquí esbozados y, sin representar una apología simplista o imposible del Psicoanálisis sino más bien una crítica que pretende ser sin fisuras, a través de un estilo arrogante y aparentemente agresivo, ofrece a la reflexión elementos importantes, para pensar cuestiones candentes del Psicoanálisis. Los puntos de partida de Voloshinov en esta tarea se basan, como introduce Wertsch (1999), en dos preceptos metodológicos básicos: una Psicología marxista debe abordar la especificidad cultural e histórica de la conciencia humana y, a un tiempo, basarse en métodos objetivos. Con estos presupuestos de partida, la noción de inconsciente que pretende desarrollar Voloshinov no se fundamentará en supuestos contenidos instintuales sino que, en una lectura novedosa del descubrimiento freudiano, y en línea con la tesis de Engels de que la conexión entre lenguaje y trabajo representa una vía privilegiada para la comprensión de la conciencia, se trata de un inconsciente lingüístico y dialógico, con un claro origen social, que muestra claramente, como también se esforzó en demostrar Gramsci (1971), el carácter contradictorio de la conciencia.

Las críticas posteriores a este abordaje del freudismo han coincidido en diversos elementos comunes que apuntan a la utilización de argumentos que no resisten el paso del tiempo, excesivo objetivismo y materialismo ingenuo, parcialidad, desconocimiento en profundidad de la teoría freudiana, que configurarían un enfoque, como afirma Wertsch (1999, p. 19), "abiertamente polémico, insuficientemente específico y, en algunos puntos, sencillamente anticuado". Para Bruss (1999), se trataría de un encuentro a destiempo, demasiado temprano entre las dos disciplinas, marxismo y Psicoanálisis, que refleja una lectura bastante limitada y estereotipada por parte de Voloshinov. Se explicitan toda una serie de limitaciones en el enfoque de Voloshinov que resalta el excesivo determinismo social esgrimido que resta importancia al dinamismo psíquico, la insistencia en la continuidad psíquica y rebaja del protagonismo de la dinámica inconsciente, la sobreestimación de la confianza del Psicoanálisis en la introspección, el reduccionismo social del conflicto psíquico, un excesivo énfasis del nivel macrosocial en detrimento de los efectos de estructuras sociales concretas, familia, grupos de pares, etc., entre otras cuestiones. Independientemente de estas críticas, y desde nuestro punto de vista, es en su escueta referencia a la proximidad posible entre inconsciente y cambio social, así como en la original concepción lingüística del inconsciente, donde Freudismo alcanza su mayor atractivo y abre las más interesantes posibilidades para la reflexión que nos dirigen más allá de la mayoría de abordajes de la relación entre lo psíquico y lo social. En este sentido, coincidimos con Zavala (1991) cuando resalta la necesidad de valorar en su conjunto el texto único del círculo bajtiniano, del que esta polémica temprana sería un claro antecedente, en torno a dos preguntas esenciales con múltiples implicaciones comunes y con clara, también, vocación lacaniana, una teoría del sujeto y una teoría del lenguaje. 
Así consideramos que, a pesar de que la crítica considera Freudismo como una obra menor dentro del entramado de la producción del círculo de Bajtin, se trata de un texto adelantado a su tiempo, aunque radicalmente sujeto también a unas condiciones sociohistóricas determinadas, y así algunas de las cuestiones presentes en éste han interrogado reiterativamente el desarrollo del Psicoanálisis a lo largo del siglo XX. Podemos afirmar incluso que Voloshinov se anticipa, más bien con sus preguntas, con los elementos que organizan el debate ofrecido, que con las respuestas finales, a la propia dinámica reflexiva del movimiento psicoanalítico internacional respecto a la concepción del inconsciente, la naturaleza del vínculo social, las implicaciones políticas, etc., así como a la relación con los movimientos intelectuales que, desde bases diversas, comparten espacios limítrofes con el Psicoanálisis. Por otra parte, comparte Freudismo igualmente con otras obras aparecidas inicialmente con la firma de Voloshinov y Medvedev dudas sobre su autoría real, en muchos casos, resueltas a favor de M. Bajtin, como autor global. En este sentido, es interesante recordar el criterio de Glück que resalta la genuina orientación marxista en los trabajos de esos dos autores frente a otros escritos emanados del grupo de Leningrado, si bien hemos de reconocer también la similaridad de ideas matrices entre estas producciones.

Hay que tener también presente la fecha de publicación que data de 1927 y el hecho de que alguna de las obras de Freud, que desarrollan más directamente cuestiones marcadamente sociales y culturales, no estuvieran al alcance de Voloshinov en la época de redacción de este bosquejo crítico. Sí lo estuvo, y aquí la disculpa a una lectura insuficiente y sesgada se hace más difícil, la obra de Freud Más allá del principio del placer, que marca un punto de inflexión importante en la teoría psicoanalítica, aunque también hemos de reconocer que para la mayoría de los posfreudianos se trata de un texto complejo, difícilmente integrable en el ideal normativizador que fue norte para el Psicoanálisis exiliado en los Estados Unidos. Es más, para su objetivo crítico, Voloshinov desecha las posibles implicaciones de las contribuciones freudianas a la elaboración de una teoría del goce pulsional, más allá de la simple concepción biologicista de las necesidades, y se recrea, por ejemplo, la evolución de las hipótesis freudianas a la, como el propio autor denomina, "magnífica reductio ad absurdum" del trauma del nacimiento de Rank (1994). Asimismo, la obra que recibe nuestra atención en este apartado viene precedida por la publicación de Más allá de lo social (acerca del freudismo), firmada por Voloshinov en el periódico Zvezda en 1925 y donde es cuestionada la doctrina psicoanalítica y la compatibilidad apologética defendida por algunos coetáneos con una posible Psicología marxista. Pero a pesar de la coincidencia inicial de partida de ambos textos, Titunik (1999) nos advierte que existe una diferencia entre ellos, de especial interés para la cuestión que nos ocupa. En el artículo de 1925, donde aparecen la gran mayoría de elementos de ataque materialista contra el freudismo, no se encuentra, sin embargo, orientación alguna hacia la preeminencia del lenguaje y de la teoría discursiva en la concepción del inconsciente que va a ser considerada tan premonitoriamente atractiva en el libro de 1927. Es innegable que Freudismo muestra un elevado interés crítico por la concepción freudiana, tanto respecto al periodo de formación de los pilares teóricos del mismo, cuanto a la estructuración del propio movimiento psicoanalítico. Sin embargo, los propios presupuestos de recepción del Psicoanálisis entre los componentes del círculo de Bajtin, nos llevan a entrar en contacto directo con el problema de las reacciones verbales y de su significado dentro del comportamiento y la psique humana; es decir, con uno de los problemas más importante y más difíciles de la propia construcción de la Psicología como disciplina científica. Falta en Más allá de lo social uno de los principios rectores y la principal línea argumentativa que otorga a Freudismo su originalidad frente a la caducidad de otros argumentos críticos mucho menos atractivos. De hecho, en el texto de 1925 la dirección del desarrollo de una ciencia psicológica marxista, que en Freudismo será matizada, se encontraba en las investigaciones de marcada orientación fisioquímica sobre reflejos y tropismos, poniendo como condición a la definición científica de inconsciente 
que éste fuera concebido solo a partir de procesos de tipo somático y material.

\section{Argumentos críticos: el estrecho margen entre objetivismo y materialismo}

Lo que podemos denominar el "giro lingüístico" reflejado ya claramente en Freudismo, está mediatizado por la aparición, en 1926, de un nuevo artículo firmado también por Voloshinov y aparecido en el número seis de la misma publicación, Zvezda, titulado La palabra en la vida y la palabra en la poesía (Cuestiones concernientes a la poética sociológica), incluido con acierto como anexo a Freudismo en el volumen traducido al castellano publicado en 1999. Aquí Voloshinov expresa enfáticamente una orientación cardinal respecto a la triada lenguajediscurso-palabra como la clave para el estudio de todas las formaciones ideológicas de la vida y de la cultura humana. Como afirma Ponzio (1998), es esta consideración de la estructura lingüística del inconsciente la que aproxima, independientemente de su parcialidad y caducidad, este bosquejo crítico a lo que Lacan ha contribuido a poner de manifiesto en la obra freudiana, con relación a que el análisis del inconsciente conlleva inevitablemente una aproximación a partir de la palabra y el lenguaje, pudiendo establecer, incluso ya desde etapas muy iniciales de la producción freudiana, una fuente en común entre síntomas y uso lingüístico. También Ponzio (1998, p. 71) nos aclara que esa "fuente en común" Voloshinov la sitúa en la materialidad ideológica-sígnica que constituye tanto la conciencia social cuanto la psique individual, referida ésta tanto a la conciencia oficial como a la posibilidad de una conciencia no oficial. El trabajo de traducción del lenguaje de los sueños a expresión diurna no queda, para Voloshinov, fuera de la cadena de signos ideológicos, puesto que se resalta la continuidad entre psique individual e ideología institucionalizada. El signo no es solo una sombra, un mero reflejo de la realidad, es más bien una parte de esa realidad y como tal es un segmento tan natural como cualquier otro objeto natural o construido por los hombres. De hecho, su mayor característica es la mediación entre dos realidades, constituyendo el discurso verbal un escenario para un evento determinado. Frente a los demás objetos no sígnicos, el signo se fundamenta en la representación, se caracteriza por estar en el lugar de otra cosa diferente de sí mismo. Pero del mismo modo, al tiempo que el signo se combina con la realidad donde es usado, tiene la capacidad de transformar esa misma realidad en algo nuevo, algo distinto de aquello con lo que contábamos anteriormente a que el signo fuese introducido. Del mismo modo, la dialéctica de la significación implica también que el nuevo contexto se introduzca en el signo, amplificando su significado. Junto a la presencia física y al representar a otra cosa será necesaria una tercera condición relativa al punto de vista valorativo (Ponzio, 1998), con su correspondiente contexto, parámetros, plan de acción y perspectiva de praxis. Es desde esta perspectiva que se afirma que el signo es siempre ideológico y asimismo lo ideológico es un producto social. Todo lo que forma parte de la realidad material puede convertirse en signo, adquiriendo dicho valor exclusivamente en la dimensión históricosocial. Voloshinov, en su ensayo La palabra y su función social de 1930, describe cómo el elemento esencial de la transformación de objetos y fenómenos materiales en signos es el propio cuerpo humano, como material primario que concede función sígnico-ideológica a un fenómeno u objeto perteneciente a la realidad material "extracorporal” (Ponzio, 1998, p. 102). El cuerpo, el gesto, la voz, son entendidos como material de expresión valorativa que se manifiesta con el material que le es externo. Es condición necesaria la unión efectiva o posible entre el cuerpo y cualquier otro objeto material externo, para que éste pueda convertirse en signo. De cualquier modo, todo objeto o fenómeno se convierte en material sígnico-ideológico, incluido el cuerpo, solamente en la relación intersubjetiva inherente a la organización social.

En términos generales, Voloshinov (1999), en el desarrollo del capítulo VII de Freudismo, considera al Psicoanálisis como una aventura epistemológica fallida, a partir de críticas variadas aunque integrables en una lectura objetivista y materialista del descubrimiento freudiano, que iremos desgra- 
nando en los próximos párrafos. Críticas programáticas, la mayoría de ellas, que no ocultan una cierta desilusión respecto a la supuesta desviación en la construcción del gran edificio que es el Psicoanálisis desde los cimientos materiales, verdaderos motivos de la conducta. Escribe Voloshinov (1999, p. 137) que Freud "ha tratado de erigir un edificio completamente nuevo, cuasi objetivo, de la psique humana, a partir de los antiguos ladrillos subjetivistas".

Así Voloshinov plantea la propia evolución del Psicoanálisis, al margen del debate entre Psicología objetiva y subjetiva, más como un efecto de repliegue y sectarismo del mismo que como acción efectiva por parte del marco epistemológico y práctico que sustenta la práctica psicoanalítica. De hecho, el Psicoanálisis no sale muy bien parado en esta operación y acaba transfiriendo a sus constructos todos los defectos fundamentales de la Psicología subjetiva. Contra la opción subjetivista se enfrentan en este análisis crítico las "cosas reales" (Voloshinov, 1999, p. 139), los datos objetivos y materiales a los motivos de los que autoinforma el paciente sobre sus propias acciones que, en cualquier caso, remiten a sentimientos, deseos, representaciones, que no serán más que reflejos ideológicamente distorsionados en el nivel de la conciencia. El Psicoanálisis articularía su visión de la vida psíquica sobre conflictos variados de motivos, que ilusoriamente empañan y se distancian de las fuerzas reales objetivas que subyacen a ese tipo de conflictos y de las que la autoconciencia no está en absoluto advertida. Al hablar de consciente, preconsciente, inconsciente, Freud no haría otra cosa que referirse a nuestras contradicciones con nosotros mismos, pero sin salir de los límites de la configuración subjetivista de la conciencia y de la noción de vida psíquica que de ésta se derivaría. Para Voloshinov (1999, p. 138) el deseo inconsciente no es más que "un nuevo ladrillo", para fortificar la base del viejo edificio de la Psicología humana, pues la brecha abierta entre la esfera subjetiva interna y la material sigue siendo en el Psicoanálisis exactamente la misma que en la Psicología de la conciencia, como un mero intento de psicologización de lo somático, sin tener en absoluto presente el marcado carácter ideológico de los mecanismos psíquicos descritos por Freud. Este proceso sería manifiesto en todas las formulaciones freudianas que en general siguen su curso dentro de los límites de la psique subjetiva vista como entidad aislada, sin la necesaria referencia a ningún tipo de condición material.

Sin embargo, Voloshinov (1999, p. 143) reconoce algo paradójicamente nuevo y original en la lectura psicoanalítica de la dinámica de la psique, y es la referencia nuclear a "la lucha, el caos, el antagonismo" de ésta. Es aquí donde se detecta la distinción fundamental del Psicoanálisis respecto a la mayoría de tendencias tradicionales de la Psicología. Sin embargo, también aquí Voloshinov tiene sus dudas, pues critica el tipo de fuerzas que para Freud entran en conflicto. En este punto se desarrolla la estrecha conexión que Voloshinov concibe entre Psicoanálisis y lenguaje y, que según su perspectiva, pasa desapercibida para el movimiento psicoanalítico. Todo constructo psicológico freudiano se basa fundamentalmente en manifestaciones verbales humanas, no siendo más que un tipo especial de interpretación de estas expresiones verbales. Así, Freud no toma los enunciados en su aspecto objetivo, no busca sus raíces materiales, psicológicas o sociales, sino que intenta encontrar los verdaderos motivos de la conducta en las expresiones mismas, suponiendo que el propio paciente suministra información sobre las profundidades del inconsciente. Aquí se hace patente el sesgo de Voloshinov (1999, p. 145) en la concepción de la asociación libre como mera introspección, afirmando que Freud dirige ésta, por nuevos caminos, dirigiéndose a nuevas esferas de la psique, pero sin renunciar "a la introspección misma como único método para autentificar la verdad de los hechos psíquicos". Así, también el inconsciente es incluido en el ámbito de la introspección, siendo el propio paciente el que debe recordar el contenido inconsciente y atestiguar su existencia con la ayuda de la técnica introspectiva. Para la introspección, todas las producciones del inconsciente toman la forma de deseos o impulsos, encuentran su expresión verbal de esa manera, entrando en la conciencia bajo la apariencia de un motivo, en clara alusión a 
la terminología kantiana para la distinción de los fenómenos mentales. La crítica a la introspección se amplía, asimismo, con una crítica sobre el uso del método retrospectivo (por ejemplo en el recurso al complejo), basándose en la interpretación de los recuerdos de los adultos y de las formaciones de compromiso con cuya ayuda se puede llegar hasta dichos recuerdos. Para Voloshinov (1999, p. 147), es evidente que "el sistema de Freud no nos da acceso a la base fértil de la aprehensión objetiva", ya que desde esa práctica no puede llegarse a nada real, a nada objetivo, pues se trata exclusivamente de la interpretación del pasado desde el punto de vista del presente. Así, el constructo del complejo, en especial el de Edipo, pasa a ser criticado como formulación puramente ideológica proyectada sobre la psique del niño.

\section{La dimensión ideológica}

La dinámica psíquica en Freud se reduciría pues, desde la crítica a la que Voloshinov la expone, a una mera dinámica de los diversos motivos de la conciencia, siempre bajo la iluminación ideológica de la conciencia misma. Sólo sería posible oír la voz tendenciosa de la conciencia subjetiva que interpreta la conducta humana. El inconsciente no puede ser considerado más que uno de los motivos de esa conciencia, uno de sus recursos para interpretar ideológicamente la conducta. Al respecto, se pregunta Voloshinov (1999) en el capítulo IX de Freudismo, qué es la conciencia de un ser humano si no la ideología de su conducta; ideología en sentido estricto, pues una ideología despista a quien no sabe ir más allá, hasta el juego oculto de las fuerzas materiales objetivas subyacentes, reales condiciones económicas y sociales.

Así, las condiciones objetivas de la conducta apuntan a las dimensiones fisiológicas y socioeconómicas. Pero frente a ello, Freud se dejaría arrastrar por el conflicto de las motivaciones subjetivas de la conciencia, por lo que la teoría freudiana remitiría a una proyección de ciertas relaciones objetivas del mundo externo sobre el mundo de la psique.
En esta línea de argumentación, Voloshinov (1999, p. 158) insiste en que "cualquier manifestación verbal es producto de la interacción entre locutores y del contexto más amplio de la situación social total y compleja en la que surge" (cf. El discurso en la vida y el discurso en el arte, 1926). Cualquier producto de la actividad del discurso humano deriva en forma y significado, en sus aspectos más esenciales, no de las experiencias subjetivas del hablante, sino de la situación social en que aparece. Se podría definir el discurso entonces como el guión del acto inmediato de comunicación en cuyo proceso es engendrado, siendo éste a su vez un factor del campo global de la comunicación de la comunidad a la que el locutor pertenece. Todas las manifestaciones verbales del paciente, de las que depende el sistema psicológico propuesto por Freud, serían discursos (guiones) del pequeño acontecimiento social inmediato en el cual son engendrados, esto es, la sesión analítica. Las resistencias, por ejemplo, son, para Voloshinov, principalmente resistencias análogas al médico, al oyente, a la otra persona en general. Los mecanismos psíquicos descubren, por tanto, su origen social. Es así como el sistema freudiano proyecta, sobre la psique individual, toda la dinámica de la interrelación entre dos personas.

¿Qué queda entonces por tanto de la dinámica de la psique? Voloshinov (1999, p. 162) se responde que quedan los conflictos en el seno de la conducta verbalizada de los seres humanos, pues "no se trata de conflictos psíquicos sino ideológicos $y$, en consecuencia, no pueden entenderse dentro de los límites estrechos del organismo y la psique individuales". Una lucha de motivos, pero no una verdadera lucha, una lucha de fuerzas naturales. Detrás de ese tipo de luchas, como en cualquier lucha ideológica, sea cual fuere su escala, se hallan encubiertas ciertos procesos materiales objetivos. Algunos de estos hechos conductuales objetivos, en el caso de la psique, son básicamente de naturaleza fisiológica, aunque su estudio a través de los métodos reflexológicos no nos lleva demasiado lejos en la explicación de la conducta humana. En cualquier caso, respecto a lo que llamamos psique o conciencia se nos impone una consideración ri- 
gurosa y completa de los factores socioeconómicos en juego, reflejando la dialéctica de la historia en mayor medida que la de la naturaleza. La naturaleza aquí presente es ya una naturaleza refractada por lo económico, los social, lo discursivo, en suma, dándole al término discurso, más que su extendido y estrecho sentido lingüístico, un amplio y concreto sentido sociológico, como ambiente objetivo donde se presenta el contenido psíquico. Es ahí donde se componen y adquieren expresión externa los motivos de la conducta, los argumentos, las metas y las evaluaciones. Es también en esa esfera concreta donde surgen los conflictos entre ellos. Aquí, es de resaltar el esfuerzo y la exigencia de Voloshinov de crear una Psicología materialista objetiva, sin caer víctima del reduccionismo fisiológico, todavía en boga entre los académicos contemporáneos, aunque más tarde fuera estigmatizado como "materialismo vulgar".

Voloshinov está de acuerdo con Freud en la crítica que éste realiza a la Psicología de la conciencia, pero dice también ir más allá al considerar que tampoco los motivos inconscientes explican la conducta pues éstos no difieren fundamentalmente de la conciencia, considerándolos solo una distinta expresión ideológica de la conciencia: los motivos del inconsciente son sólo reacciones verbales del paciente, a igual título que todos los otros motivos comunes de la conciencia. Desde esta perspectiva, el inconsciente de Freud podría denominarse "consciente no oficial" y ambos conjuntos de motivos (los del consciente oficial y no oficial) se dan de un modo totalmente análogo en el habla interna y externa. También en este punto es necesario reconocer la posición osada del autor, pues en el contexto de la "lucha por la conciencia" que Vigotsky y otros estaban librando, él se decanta por una epistemología radicalmente social, no tanto como resultado de la generalización de los desarrollos individuales, sino como verdadero punto de partida (Bakhurst, 1990).

En esta tarea compleja desiste de apoyar sus argumentaciones sobre la base cognitiva de la relación pensamiento-lenguaje y el enfoque microsocial, para ofrecer, en cambio, un análisis semiótico de la psique y la propia condición humana, haciendo presente, de manera reiterativa, la idea de que en la comunicación humana toda manifestación verbal es un fenómeno irreductiblemente social. De cualquier modo, se ha intentado también trazar algunas conexiones de interés entre la tesis de Vigotsky en Pensamiento y lenguaje y la hipótesis del inconsciente freudiano. Así, Vigotsky (1982) entiende que el origen de la secuencia de desarrollo del pensamiento verbal hay que situarlo en el motivo, la emoción, a partir de la que se genera un pensamiento, dando forma a partir de la interacción lingüística al discurso interior, al significado y finalmente a las palabras. Las características del discurso interior presentarían algunas similitudes básicas con los mecanismos inconscientes propuestos por Freud: condensación, en forma de abreviación y aglutinación de palabras, desplazamiento de sentido entre palabras, preeminencia del sentido, etc. Como reflejo del habla interior, el inconsciente puede ser reinterpretado como construcción social, efecto mediatizado por las interacciones sociales desde los primeros encuentros del lenguaje con el territorio afectivo, motivos y emociones. La familia como primer escenario social del desarrollo emocional del niño, se convierte, por tanto, en espacio privilegiado para la dimensión inconsciente.

La implicación a este respecto es clara y apunta a que toda manifestación verbal es producto de la interacción entre locutores y del contexto más amplio de la situación social total y compleja de la que surge. Evidentemente, se anticipan en estas palabras algunos elementos definitorios que caracterizarán la aproximación bajtiniana. Voloshinov (1999) añade:

Cualquier enunciado en voz alta o escrito para su comunicación inteligible es la expresión y el producto de la interacción social de tres participantes: el locutor (el autor), el oyente (el lector) y el tema (el quien o qué) del habla (el héroe). El discurso es un hecho social; no está autocontenido como una magnitud lingüística abstracta, ni es posible derivarlo psicológicamente de la conciencia subjetiva del locutor considerada aisladamente. (p. 184). 
Desde esta perspectiva, el concepto de inconsciente, incluso el fenómeno de la represión, no pueden ser considerados categorías por fuera del tiempo y el contexto, pues cada sociedad, cada ámbito sociohistórico determina el sentido y la ausencia de éste, así como aquello que debe quedar relegado del ámbito conversacional. La vivencia, tanto lo expresado como su objetivación externa, están constituidas por el mismo material. No hay vivencia fuera de la encarnación sígnica, fuera de lo simbólico, quedando vedado el acceso a todo lo que está más allá de la vivencia. El sujeto entonces solo puede existir en un mundo objetivo, un mundo de mediaciones que lo crean en tanto tal. A su vez, las objetivaciones, los símbolos y las palabras son puestos siempre en juego, por sujetos concretos determinados históricamente. El resultado de la significación y la comprensión de tales objetivaciones dependerán siempre del intercambio y la práctica intersubjetiva. Recordemos, a este respecto, que el lenguaje en la semiótica bajtiniana quedará definitivamente concebido como dialógico, práctico e histórico. Así, cada acto de habla estará determinado por un entrecruzamiento, una lucha entre sujetos hablantes en torno a la propia materialidad que los soporta, más allá de lo estrictamente simbólico.

Insiste igualmente Voloshinov (1999) en su opúsculo sobre El discurso en la vida y el discurso en el arte (acerca de la poética sociológica) en que el contenido del componente verbal de la conducta, está determinado en todos sus aspectos fundamentales y esenciales por factores sociales objetivos; así el discurso, lo verbal no es propiedad de un sujeto sino de su grupo social. Al tomar conciencia de uno mismo, tratamos de vernos a través de los ojos de otra persona, de otro representante del grupo o la clase social. De este modo, la autoconciencia siempre nos lleva a la conciencia de clase, de la cual es reflejo y especificación en sus aspectos fundamentales y esenciales. Aquí aparecen las raíces objetivas de, incluso, las reacciones más personales e íntimas. En la realidad no hay línea divisoria fundamental entre el contenido de la psique individual y la ideología formulada.
Voloshinov (1999, p. 161) llega a afirmar que una manifestación verbal humana es un constructo ideológico en pequeño. Así se plantea un nuevo concepto, "ideología conductual", referido a ese habla interior y exterior que impregna toda nuestra conducta; ideología, por otra parte, en ciertas facetas más sensible, responsiva, excitable y vivaz que una ideología ya formulada, que se ha vuelto oficial. Los conflictos psíquicos freudianos, en relación a este argumento, los lapsus, los sueños, los síntomas, chistes, etc., podrían ser referidos a conflictos ideológicos, lucha de diversas tendencias ideológicas que toman forma dentro de la ideología conductual. Las áreas de la ideología conductual correspondiente al consciente "censurado" oficial expresaría los factores más constantes y dominantes de la conciencia de clase; estaría, por tanto, en línea con la ideología formulada, plenamente desplegada de la clase de la que se trata, su ley, su moral, su visión del mundo, etc. En estos niveles, el habla interior es fácilmente ordenable y expresable libremente como habla externa o, en todo caso, no teme convertirse en habla externa. Otros niveles, sin embargo, correspondientes al inconsciente, están a gran distancia del sistema estable de la ideología dominante. Estos presagian la desintegración de la unidad e integridad del sistema, revelando la vulnerabilidad de las motivaciones ideológicas habituales. Se trata de motivos interiores que erosionan la unidad de la ideología conductual, cuya acumulación puede tener simplemente carácter incidental y solo atestiguar de la asunción de un estatus social desplazado en el nivel individual, pero también comúnmente puede testimoniar de la desintegración emergente, si no de la clase social como un todo, por lo menos de algunos de sus grupos. Aquí queda patente la dificultad operativa para ir de lo particular a lo social. De hecho, Voloshinov se refiere de manera sumamente escueta y precipitada a esta posibilidad. El contenido y la composición de los niveles no oficiales de la ideología conductual (inconsciente) estarán condicionados por la época histórica y la clase. 


\section{Perspectivas e influencias contemporáneas}

Como describe recientemente Branney (2008), desde finales de la década de 1980 se viene desarrollando una corriente particular dentro de la Psicología discursiva que pretende combinar el análisis del discurso con aportaciones de la teoría psicoanalítica. Concretamente la influencia de Voloshinov, cuyo legado junto a las aportaciones generales del círculo de Bajtin, comienza a revitalizarse desde esta perspectiva, se deja sentir en algunos intentos recientes por reconceptualizar el inconsciente o la represión desde una perspectiva psicosocial. Así Billig $(1997,1998,1999)$ plantea las relaciones entre Psicoanálisis y Psicología discursiva, sobre la base de que los fenómenos psicológicos responden, más que a procesos internos, a actividades discursivas, intersubjetivas, sujetas a las pautas de la interacción conversacional. La propia interacción conversacional no es únicamente un modo de expresión, sino también una forma represiva, que será el fundamento de la noción de inconsciente dialógico. Las aportaciones del ámbito de estudio, conocido como análisis conversacional, le dan pie para afirmar que tanto lo consciente como lo inconsciente está constituido en la propia interacción cotidiana, en la que no sólo hacen su aparición las normas morales, sino ciertas "tentaciones inmorales" que generalmente el propio dispositivo conversacional tiende a reprimir. Para Billig (1997), la represión debe ser entendida entonces a partir de la interacción social discursiva. Frente a esta pretensión el autor vislumbra un sesgo marcadamente individualista en la definición original que Freud ofrece del inconsciente y la represión, y que será continuada en la herencia posfreudiana. Tampoco le convence la elaboración posterior de Lacan al respecto. De hecho a pesar de que se prima la vertiente significante del inconsciente, explícitamente se rechaza también que la noción de inconsciente dialógico tenga raíz lacaniana, pues para Billig la relación establecida por Lacan entre lenguaje e inconsciente da prioridad a la langue como estructura lingüística total frente a la palabra; justificación ésta que se nos antoja sumamente peregrina, teniendo en cuenta que la aproximación dialógica parte de un enfoque discursivo. Hechas estas consideraciones, Billig (1997, 1999) intenta demostrar cómo el inconsciente dialógico comprende palabras que pudiendo haber sido dichas se han mantenido como indecibles, han sido dialógicamente reprimidas de un escenario conversacional particular, para así poder mantener el objetivo fundamental de progreso y respeto recíproco de cualquier interacción dialógica. Será necesario, por tanto, estudiar no sólo las presencias, sino también, y de manera especial, las ausencias lingüísticas en la interacción dialógica. Desde esta perspectiva, el inconsciente sería fruto de una dialéctica de moralidad/inmoralidad social. A partir del descubrimiento freudiano se hace necesario acompañar el estudio del aprendizaje de rutinas y códigos morales recíprocos propios de la interacción conversacional, con especial atención a ciertas irrupciones amorales de este preciado orden social, que apuntarían a la existencia de una "esfera desconocida del deseo", más que a accidentes fortuitos de la actividad lingüística. Los códigos y estructuras morales imperantes en el fenómeno conversacional, que es la clave de nuestra interacción social, obligan, inhiben, pero hay elementos que no pueden ser dominados totalmente. La represión no es un proceso completamente fiable: la represión es equivalente al retorno de lo reprimido. Billig (1998) retoma una noción de represión que implica, más que algo que queda oculto, aquello que es deseado como fuente de placer. La represión introduciría, por tanto, el conflicto cotidiano entre un ello dialógico (que induciría a la inmoralidad) y un superyó conversacional (dependiente de la propia estructura discursiva). Más aún, represión e inconsciente tienen su origen en el diálogo. El lenguaje es el transmisor necesario en la producción de la moralidad conversacional, aunque no sea mero vehículo de las prescripciones morales, sino que más bien construya y exija su propia moralidad del habla y consecuentemente genere sus propios deseos reprimidos. El deseo, por tanto, está constituido dentro del propio proceso dialógico.

Pero, evidentemente, las limitaciones de lectura y recepción que tiene Voloshinov de la producción 
freudiana ampliamente considerada, son también manifiestas. En palabras de Wertsch (1999, p. 19) "Freudismo no resulta muy convincente en muchas de sus críticas específicas al Psicoanálisis, sobre todo porque es abiertamente polémico, insuficientemente específico, y en algunos puntos sencillamente anticuado". La caracterización del inconsciente dialógico como fruto de la represión estructurada en el proceso lingüístico, toma un cariz distinto a partir de 1920 en el decurso de la ingente aportación de Freud al estudio del tema. Hasta entonces, la oposición entre el principio del placer y el de realidad sustentaba la teoría psicoanalítica de la represión. Así, a finales del siglo XIX, Freud entiende la histeria como un acto de vacilación moral y considera que el verdadero momento traumático, fundante del inconsciente, sería el de la aparición de una representación irreconciliable con las representaciones en las que el yo se sustenta. Pero la noción de trauma va siendo modificada gradualmente por Freud respecto a la hipótesis del inconsciente. Un reflejo de esta labor queda expuesta en los Estudios sobre la histeria, donde el trauma aparece inicialmente conceptuado en la perspectiva de la causalidad simple y directa sobre el síntoma, para pasar a ser considerado, en capítulos posteriores, desde una doble dimensión: trauma original fundante, a partir de la irrupción de lo real, y trauma ocasional como punto de partida de los síntomas. También frente a la linealidad causal, Freud reconoce que la implicación del trauma en la aparición sintomática tiene, generalmente, un efecto póstumo, retroactivo al constituir un recuerdo reprimido que actúa a posteriori.

La dimensión traumática está, sin embargo, ausente en la perspectiva dialógica, que únicamente acierta a localizar la represión, definida exclusivamente a partir de su marcada naturaleza lingüística, en el encuentro del sujeto con la realidad social dialógica que, desde los inicios de la socialización primaria, impondría un código moral de aceptación de la reciprocidad conversacional. Consecuentemente, la distinción fundante y ocasional no es tenida en cuenta en la concepción dialógica de la represión. Desde este enfoque, los mecanismos de la represión se explican a través de elementos afines al propio modelo retórico de pensamiento, que sugieren que el discurso social ofrece, en la mayoría de los casos, el modelo para el funcionamiento discursivo individual. La deliberación mental interna esta fundamentada sobre la argumentación pública. Así, el niño aprende a pensar internamente sobre la base de su participación en el debate retórico externo. Igualmente, a través de la propia participación en el diálogo, que reprime tanto como expresa, la gente irá adquiriendo lo que se denominan "habilidades de represión". Se critica a Freud el énfasis que supone desmedido sobre la modalidad de represión considerada no lingüística, la Verdrängung, que es calificada como misterio no verbal y asimilada al ello instintual, frente a la Verleugnung, que sí operaría a través del lenguaje. Se apuesta, por tanto, a una visión del lenguaje como mecanismo regulador de las prácticas morales discursivas, incluyendo en éstas la represión estructural, y a veces fallida, de la dimensión amoral inconsciente. En el aprendizaje de las habilidades dialógicas, el sujeto adquiere rutinas que serán aplicadas también a su propia vida mental. Pero, como operación no completamente fiable, ciertos pensamientos "demasiado descarados" para ser asumidos como propios en el escenario conversacional, pueden aparecer en la conciencia; el aprendiz discursivo sabe como alterar el sujeto de la acción, como atribuir a otro agente esos pensamientos o como canalizarlos a través del chiste, u otra formación de compromiso social.

Aun así, ha de reconocerse que muchas de las ideas reflejadas van más allá que la mayoría de enfoques históricos en su abordaje de la relación entre la psique y lo social. La defensa oficialista a las críticas de Voloshinov puede muy bien ser representada por Bruss (1999) quien habla de un encuentro a destiempo entre el materialismo dialógico representado por el ruso y el movimiento psicoanalítico. Por nuestra parte, no transitaremos ese camino y sí insistiremos en la intuición de Voloshinov para captar la clara implicación lingüística de la hipótesis freudiana del inconsciente, implicación que llevará a Lacan (1977, p. 58) a afirmar que Freud se anticipa incluso al nacimiento contemporáneo de la lingüística, con la expresión "el inconsciente 
es la condición de la lingüística", correlativa a su conocido lema el lenguaje es la condición del inconsciente. Hay aspectos diversos que distancian, pero también aproximan la definición lingüística del inconsciente en Voloshinov y Lacan, no solo a la luz de Freudismo, sino también de Marxismo y Filosofía del Lenguaje de 1929. Uno de los más interesantes es, sin duda, el empleo de una epistemología social en el acercamiento al inconsciente freudiano que en Lacan tendrá un marcado carácter transindividual y en Voloshinov se verá orientada por el antagonismo ideológico y la influencia contextual, cultural e histórica, de la vida social.

La moda bajtiniana se extiende por Occidente en el último cuarto del siglo XX, estando su recepción fuertemente marcada por el propio contexto intelectual imperante en la época, entre cuyos elementos definitorios se podrían señalar: la crisis del estructuralismo, la recepción diversa del formalismo y posformalismo del antiguo bloque soviético, la influencia irregular también de la teoría del discurso, y el legado lacaniano frente a la esclerotización del Psicoanálisis oficialista. En nuestro caso, resulta estimulante el creciente interés por la fórmula Lacan-Bajtin, incluidas, como no, las aportaciones de Voloshinov, que en castellano han desarrollado, con múltiples implicaciones, autoras como Zavala (1991) y Rodríguez-Monroy (1999).

\section{Referencias}

Acanda, J. L. (1998). La confluencia que se frustró: Psicoanálisis y bolchevismo. Temas, 14, 107-120.

Angelini, A. (2008). History of unconscious in Soviet Russia: From its origins to the fall of the Soviet Union. The International Journal of Psychoanalysts, 89(2), 369-388.

Bakhurst, D. (1990). Social memory in Soviet thought. En D. Middleton \& D. Edwards (Eds.), Collective remembering (pp. 203-226). Londres: Sage.

Billig, M. (1997). The dialogical unconscious: Psychoanalysis, discursive psychology and the nature of repression. British Journal of Social Psychology, 36, 139-159.
Billig, M. (1998). Dialogical repression and the Oedipus complex: Reinterpreting the Little Hans Case. Culture $\mathscr{E}$ Psychology, 4(1), 11-47.

Billig, M. (1999). Freudian repression. Conversation creating the unconscious. Cambridge: Cambridge University Press.

Branney, P. (2008). Subjectivity, not personality: Combining discourse analysis and Psychoanalysis. Social Personality and Psychology Compass, 2(2), 574-590. doi: 10.1111/j.1751-9004.2007.00068.x

Brenner, F. (1999). Intrepid thought: Psychoanalysis in the Soviet Union, II. World Socialist Web Site. Recuperado el 12 de abril de 2008, de http://www.wsws. org/articles/1999/jun1999/freu-j11.shtml

Bruss, N. H. (1999). V.N. Voloshinov y los presupuestos básicos de Freudismo en su relación con el estructuralismo [Apéndice III]. Freudismo. Un bosquejo crítico. Buenos Aires: Paidós.

Cole, M. (Ed.). (1986). Escritos seleccionados de A. L. Luria. Lima: Editorial Clave.

Etkind, A. M. (1994). How Psychoanalysis was received in Russia, 1906-1936. The Journal of Analytical Psychology, 39, 191-202.

Gramsci, A. (1971). Selection from the prison notebooks. Nueva York: International Publishers.

Freud, S. (1948). Obras completas (Vols. 1 y 2). Madrid: Biblioteca Nueva.

Kornilov, K. N. (Ed.). (1929) Psychologiye i marksizm. Moscú-Leningrado: Gosizdet.

Lacan, J. (1977). Psicoanálisis. Radiofonía y televisión. Barcelona: Anagrama.

Luria, A. R. (1978). The Selected Writings. White Plains, NY: M. E. Sharpe.

Parrington, J. (1997). In Perspective: Valentin Voloshinov. International Socialism, 75. Recuperado el 23 de enero de 2009, de http://pubs.socialistreviewindex.org.uk/isj75/parring.htm.

Ponzio, A. (1998). La revolución bajtiniana. Valencia: Cátedra.

Rank, O. (1994). The trauma of birth. Dover: Courier Dover Publications.

Rodríguez Monroy, A. (1999). El Saber del Traductor. Madrid: Montesinos.

Rossi-Landi, F. (1978). Ideología. Milán: Isedi. 
Titunik, I. R. (1999). Freudismo. Un bosquejo crítico [Introducción del Traductor al Inglés]. Buenos Aires: Paidós.

Trotsky, L. (1972). The revolution betrayed. Nueva York: Pathfinder Press.

Trotsky, L. (1989). Literatura y revolución. Otros escritos sobre la literatura y el arte. Buenos Aires: Ed. Crux.
Vigotsky, L. (1982). Obras escogidas. Madrid: Visor. Voloshinov, V. N. (1999). Freudismo. Un bosquejo crítico. Buenos Aires: Paidós.

Wertsch, J. W. (1999). Freudismo. Un bosquejo crítico [Prefacio]. Buenos Aires: Paidós.

Zavala, I. M. (1991). La Posmodernidad y Mijail Bajtin. Una Poética Dialógica. Madrid: Espasa-Calpe. 
